\title{
Article \\ Composite Films of Nanofibrillated Cellulose with Sepiolite: Effect of Preparation Strategy
}

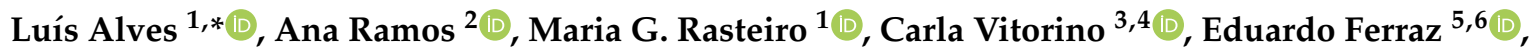 \\ Paulo J. T. Ferreira ${ }^{1}\left(\mathbb{D}\right.$, Maria L. Puertas ${ }^{7}$ and José A. F. Gamelas ${ }^{1, * \mathbb{C}}$
}

1 CIEPQPF, Department of Chemical Engineering, University of Coimbra, Rua Sílvio Lima, Pólo II, PT-3030-790 Coimbra, Portugal; mgr@eq.uc.pt (M.G.R.); paulo@eq.uc.pt (P.J.T.F.)

2 FibEnTech, Departament of Chemistry, University of Beira Interior, Rua Marquês d'Ávila e Bolama, PT-6201-001 Covilhã, Portugal; ammr@ubi.pt

3 CQC, Department of Chemistry, University of Coimbra, Rua Larga, PT-3004-535 Coimbra, Portugal; csvitorino@ff.uc.pt

4 Faculty of Pharmacy, University of Coimbra, PT-3000-548 Coimbra, Portugal

5 Techn\&Art, Polytechnic Institute of Tomar, Quinta do Contador, Estrada da Serra, PT-2300-313 Tomar, Portugal; ejmoferraz@ipt.pt

6 Geobiotec, Geosciences Department, University of Aveiro, Campus Universitário de Santiago, PT-3810-193 Aveiro, Portugal

7 Tolsa, SA, Research \& Technology for New Businesses, Ctra. de Madrid a Rivas Jarama, 35, ES-28031 Madrid, Spain; mpuertas@tolsa.com

* Correspondence: luisalves@ci.uc.pt (L.A.); jafgas@eq.uc.pt (J.A.F.G.)

check for

updates

Citation: Alves, L.; Ramos, A.; Rasteiro, M.G.; Vitorino, C.; Ferraz,

E.; Ferreira, P.J.T.; Puertas, M.L.; Gamelas, J.A.F. Composite Films of Nanofibrillated Cellulose with Sepiolite: Effect of Preparation Strategy. Coatings 2022, 12, 303. https://doi.org/10.3390/ coatings 12030303

Academic Editors: Fengwei (David) Xie and Binjia Zhang

Received: 30 December 2021 Accepted: 16 February 2022 Published: 23 February 2022

Publisher's Note: MDPI stays neutral with regard to jurisdictional claims in published maps and institutional affiliations.

Copyright: () 2022 by the authors Licensee MDPI, Basel, Switzerland. This article is an open access article distributed under the terms and conditions of the Creative Commons Attribution (CC BY) license (https:// creativecommons.org/licenses/by/ $4.0 /)$.

\begin{abstract}
Cellulose nanofibrils (CNFs) are nanomaterials with promising properties to be used in food packaging and printed electronics, thus being logical substitutes to petroleum-based polymers, specifically plastics. CNFs can be combined with other materials, such as clay minerals, to form composites, which are environmentally friendly materials, with acceptable costs and without compromising the final properties of the composite material. To produce composite films, two strategies can be used: solvent casting and filtration followed by hot pressing. The first approach is the simplest way to produce films, but the obtained films may present some limitations. In the present work, CNFs produced using enzymatic or TEMPO (2,2,6,6-tetramethylpiperidine-1-oxyl radical) oxidation pretreatments, followed by high-pressure homogenization, or only by mechanical treatment (homogenization), were used to produce films by both the available procedures. The films obtained by filtration + hot pressing presented higher tensile strength and Young's modulus compared with those obtained by solvent casting. In general, a decrease in the values of these mechanical properties of the films and a decrease in elongation at break, with the addition of sepiolite, were also observed. However, for the TEMPO CNF-based films, an improvement in tensile strength could be observed for $10 \%$ of the sepiolite content. Furthermore, the time necessary to produce films was largely reduced by employing the filtration procedure. Finally, the water vapour barrier properties of the films obtained by filtration are comparable to the literature values of net CNF films. Thus, this technique demonstrates to be the most suitable to produce CNF-based composite films in a fast way and with improved mechanical properties and suitable gas barrier properties.
\end{abstract}

Keywords: biodegradable materials; nanocomposite films; tensile strength; Young's modulus; water permeability

\section{Introduction}

Nowadays, petroleum-derived plastics are widely used in general applications, such as food packaging and printed electronics, as well as in many other applications. The low cost of petroleum-based plastics, their excellent water barrier properties, and their suitable mechanical properties can be pointed out as the main reasons for their large use. On the other hand, the industrial production of plastic films is very well established, and 
properties with lower acceptability, for instance, oxygen barrier, can be improved by the addition of thin layers of other materials, such as ethylene vinyl alcohol, polyamide, or aluminium, largely increasing the barrier capacity [1].

However, the emerging environmental concern of the population around the world can be the driving force to change to environmentally friendly alternatives, such as cellulosebased films [2,3]. Presently, macro- and microplastics are one of the major sources of pollution in the oceans and water streams, as well as of soil pollution [4]. Thus, it is urgent to find materials suitable to substitute plastics in most of the applications, mainly for single-use purposes, such as food packaging. It is estimated that the amount of plastic raw materials used for food packaging ascends to $200 \mathrm{Mt}$ every year [5], polyethylene terephthalate, polyvinyl chloride, and polyethylene of low and high density being the most used plastics, all petroleum based. These materials are not biodegradable, since they need several hundred years to degrade in nature, resulting in a very high ecological footprint.

Bio-based alternatives, such as cellulose-based films, emerge as an interesting alternative to common plastics. Amongst the possible cellulose-based materials suitable to produce films able to substitute plastics in food packaging and printed electronics, the cellulose nanofibril-based ones constitute an interesting choice. Cellulose nanofibrils (CNFs) are attractive materials due to their excellent properties, such as large specific surface area, high stiffness and strength, low density, high biocompatibility, good film-forming capability, and biodegradability [6]. Thus, in recent years a lot of attention has been given to materials derived from CNF for different applications. However, CNFs are still quite expensive materials, mainly due to the high energy and/or chemical pretreatments, usually applied in their preparation. Additionally, the barrier properties of CNF-based materials are many times reduced, mainly in high-moisture conditions. Therefore, novel strategies are needed to overcome some drawbacks of the CNF-based materials and allow large-scale application. These strategies can involve, for example, the preparation of CNF-mineral composites $[2,7,8]$.

A brief literature survey about CNF-clay mineral composites reveals that most of the reported works have dealt with planar minerals, such as montmorillonite [2,9], vermiculite [10], and kaolinite [11]. Only a few studies reporting composites using fibrous minerals, such as sepiolite, are available. For example, Ghanadpour et al. studied the use of sepiolite to produce polyethylene/phosphorylated CNF/sepiolite composites with flame retardancy properties [12]. Fibrous clay minerals, such as sepiolite and palygorskite, present a shape similar to that of $\mathrm{CNFs}$, being composed of bundles and individual long rods with a thin diameter (up to $2-3 \mu \mathrm{m}$ in length and less than $100 \mathrm{~nm}$ in thickness [13]). This fibre shape of sepiolite could lead to a good interfibrillar interaction with CNFs and induce a lower loss of mechanical properties of the produced composites, depending on the CNF properties and the mineral content. To produce CNF-based composite films, two main techniques are available: solvent casting and filtration method, the first one being the most used, due to its simplicity and wide range of application, as well, the most used for pilot/large-scale films [14].

In the present study, the use of a fibrous clay (sepiolite), as a filler/reinforcing agent of composite films, was investigated in combination with different CNF types to produce composite films with potential application in food packaging. Additionally, the effect of the preparation method and the formulation of the composite was explored. In particular, composite films were prepared both by solvent casting, and by filtration followed by hot pressing; on the other hand, three different types of CNF were studied: one prepared using solely mechanical treatment (CNF Mec), one obtained with an enzymatic pre-treatment (CNF Enz), and one obtained with an oxidation pretreatment with sodium hypochlorite in the presence of TEMPO radical (TEMPO CNF). In addition, different levels of sepiolite incorporation (up to $50 \%, w / w$ ) were evaluated. The mechanical and optical properties were assessed for all the prepared composite films, and their microstructure was analysed by electron microscopy (SEM). Finally, the water vapour barrier properties were studied 
for the films prepared by filtration + hot pressing due to the better mechanical properties obtained for these films.

\section{Materials and Methods}

\subsection{Cellulose Nanofibril Preparation}

The three different types of cellulose micro-/nanofibrils were produced from an industrial never-dried bleached Eucalyptus globulus kraft pulp supplied by a Portuguese pulp and paper company (The Navigator Company, Cacia, Portugal) following methodologies described elsewhere $[15,16]$. The cellulose fibres were first refined at 4000 rev. in a laboratory PFI beater to make the fibrils more accessible. Afterwards, to produce TEMPO $\mathrm{CNF}$, the fibres were oxidized with $\mathrm{NaClO}$ using a ratio of $4 \mathrm{mmol}$ of $\mathrm{NaClO}$ per $\mathrm{g}$ of dry pulp and catalytic amounts of TEMPO and $\mathrm{NaBr}(0.016 \mathrm{~g}$ of TEMPO and $0.1 \mathrm{~g}$ of $\mathrm{NaBr}$ per $\mathrm{g}$ of dry pulp), according to a methodology developed by Saito et al. [17]. The oxidized fibres were filtered and washed thoroughly with distilled water until constant conductivity (close to the value of the distilled water). On the other hand, to produce enzymatic micro-/nanofibrillated cellulose, a commercial enzyme (endocellulase) was used. The beaten fibres were suspended in water ( $3.5 \%$ consistency), and the $\mathrm{pH}$ was adjusted to 5 by the addition of sodium citrate buffer. The suspension was heated to $50{ }^{\circ} \mathrm{C}$ under constant mechanical stirring, and the enzyme was added ( $300 \mathrm{~g}$ of enzyme solution per ton of dry pulp; $1.9 \mathrm{~g}$ of protein per ton). The cellulose hydrolysis was stopped after $2 \mathrm{~h}$ by heating the suspension to $80^{\circ} \mathrm{C}$ for $15 \mathrm{~min}$ to denature the enzyme. The resulting suspension was cooled to room temperature, and the treated fibres were filtered and washed with distilled water until constant conductivity. To produce the sample without pretreatment, the cellulose fibres were refined up to 10,000 rev. in the PFI laboratory beater. Finally, the pretreated and nonpretreated fibres were mechanically treated in a high-pressure homogenizer (GEA Niro Soavi, model Panther NS3006L, GEA Group Aktiengesellschaft, Düsseldorf, Germany) using two passes, first at 500 bar and next at 1000 bar. The obtained CNF samples were designated Mec (only mechanical treatment in the high-pressure homogenizer), Enz (pretreated with enzyme, followed by high-pressure homogenization), and TEMPO (pretreated by oxidation mediated by TEMPO radical, followed by high-pressure homogenization). The solid content of the obtained suspensions was $0.74,0.94$, and 0.90 (wt\%) for CNF Mec, CNF Enz, and TEMPO CNF, respectively.

\subsection{Cellulose Nanofibril Characterization}

The yield of fibrillation was determined in duplicate after centrifugation of CNF aqueous suspensions $(0.05 \mathrm{wt} \%)$ at $9000 \mathrm{rpm}$ for $30 \mathrm{~min}$. The carboxyl content was determined in duplicate by conductometric titration of aqueous suspensions of CNF (acidified to $\mathrm{pH}$ of ca. 3 using $\mathrm{HCl}$ ) with $\mathrm{NaOH} 0.01 \mathrm{M}$. The degree of substitution (DS) by carboxyl groups of the $\mathrm{CNF}$ was estimated from the CNF carboxyl content. Intrinsic viscosity measurements were performed in the CNF suspension by dissolving it in cupriethylenediamine, according to the ISO standard 5351:2010. The degree of polymerization (DP) was then calculated using the Mark-Houwink equation, with the parameters $\mathrm{K}=0.42$, $\mathrm{a}=1$ when DP $<950$ and $\mathrm{K}=2.28$, and $\mathrm{a}=0.76$ when $\mathrm{DP}>950$ [18]. The obtained CNFs were also characterized in terms of zeta potential and particle size. The zeta potential measurements were carried out in a Zetasizer Nano ZS (Malvern Instruments, Malvern, UK) to evaluate the nanofiber "surface" charge. For these measurements, $0.05 \mathrm{wt} \%$ suspensions of the different CNF samples were prepared by dilution of the stock CNF suspensions and gently transferred to the measuring cells. The particle size measurements were performed in the same equipment of zeta potential, applying the dynamic light scattering technique and using the supernatants obtained from the centrifugation of the CNF suspensions at $0.05 \mathrm{wt} \%$. The supernatants were transferred to special glass cells and measured using a $532 \mathrm{~nm}$ laser source and a detection angle of $173^{\circ}$. The reported zeta potential and particle size values consisted of an average value of 6 repetitions for each sample. The transmittance of CNF suspensions at 
$0.1 \mathrm{wt} \%$ was measured using a Jasco V550 spectrophotometer (Jasco, Tokyo, Japan), taking the transmittance value (\%) at $600 \mathrm{~nm}$.

\subsection{CNF-Based Film Preparation}

A suspension of $1.0 \mathrm{wt} \%$ sepiolite (SEP) in water was prepared from a sample supplied by Tolsa, SA (Madrid, Spain), using a high-shear disperser (Dispermat CV3-PLUS-E, VMA-Getzmann $\mathrm{GmbH}$, Reichshof, Germany) at $5000 \mathrm{rpm}$ for $15 \mathrm{~min}$. The raw sepiolite material had been obtained from the deposit of Vallecas-Vicálvaro (Madrid, Spain), and processed by dry micronization using a jet mill to break the fibre bundles down into micron-size particles (with a weighted mean value of particle size by volume, D $(4,3)$, of $12.3 \mu \mathrm{m})$.

The different films were prepared using two different approaches: by filtration followed by hot pressing ( $\mathrm{F}+\mathrm{HP}$ ) and by solvent casting (SC) (Figure 1). For the films prepared by filtration, suspensions containing $0.2 \mathrm{wt} \%$ of the different $\mathrm{CNF}$ or CNF + mineral were prepared, weighing the necessary amounts of the original suspensions of $\mathrm{CNF}$ (according to the solid content of each suspension) and the suspension of sepiolite $(1.0 \mathrm{wt} \%)$ previously described. The dispersion of CNF or a mixture of CNF with sepiolite was made in the same high-shear disperser at $1000 \mathrm{rpm}$ for $10 \mathrm{~min}$. Then, the prepared suspensions were filtered using a filtration unit purchased from Kimble Ultra-Ware Filtration Systems (DWK Life Sciences $\mathrm{GmbH}$, Mainz, Germany) and cellulose acetate membranes with $0.45 \mu \mathrm{m}$ pore and $90 \mathrm{~mm}$ diameter supplied by Filtratech. After filtration, the films were dried using a rapid dryer for laboratory sheets (Lorentzen \& Wettre, model 257, Lorentzen \& Wettre GmbH, Munich, Germany). The drying was performed using a temperature of $110^{\circ} \mathrm{C}$ for $10 \mathrm{~min}$. Films were designed to have a basis weight of ca. $40 \mathrm{~g} / \mathrm{m}^{2}$. For the preparation of films by solvent casting, suspensions at $0.2 \mathrm{wt} \%$ were prepared using the different $\mathrm{CNF}$, without and with mineral, as described above, and then poured into $9 \mathrm{~cm}$ plastic petri dishes and left to dry at $40{ }^{\circ} \mathrm{C}$ in an oven. Due to volume limitations of the dishes, only films with ca. $25 \mathrm{~g} / \mathrm{m}^{2}$ were prepared using this technique. Although films with different basis weights were prepared by the two techniques, the major role was played by the preparation method and by the ratio clay/CNF, and not by the basis weight of the film.

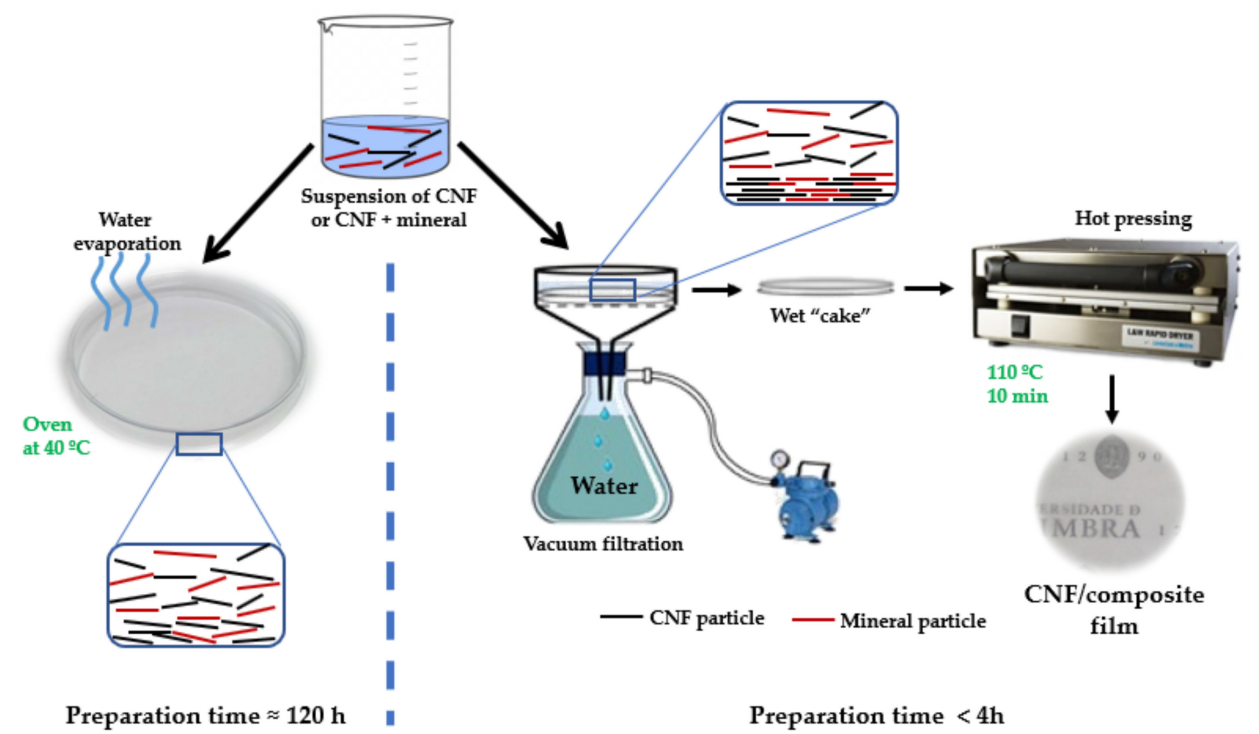

Figure 1. Illustration of the procedures used to prepare the CNF-based composite films.

\subsection{CNF-Based Film Characterization}

The basis weight of each prepared film was determined by dividing the mass of the dried film (at $40^{\circ} \mathrm{C}$ for the SC films and at $110^{\circ} \mathrm{C}$ for the $\mathrm{F}+\mathrm{HP}$ films) by the respective area. Thickness was measured using a micrometre (Adamel Lhomargy, model MI 20, 
Roissy-en-Brie, France); 10 measurements were made for 2 replicate films, and the reported value corresponded to the average of these measurements. The transparency of the films was determined according to the ISO 22891 standard, using a Technidyne Color Touch 2 spectrophotometer (Technidyne Corporation, New Albany, Indiana, USA); 2 replicate films were measured by applying the illuminant D65 and the observer $10^{\circ}$. Tensile tests were performed according to the ISO 1924- 1 standard at $23 \pm 1{ }^{\circ} \mathrm{C}$ and $50 \pm 2 \% \mathrm{RH}$. The tests were performed in a tensile tester (Thwing-Albert Instrument Co., EJA series, West Berlin, NJ, USA) with the following setup: an initial gap between grips of $5 \mathrm{~cm}$ and a tensile rate of $5 \mathrm{~mm} / \mathrm{min}$. Tensile strength and Young's modulus as well as strain at rupture were measured, and the reported values reflect the average of four specimens for each film type. Scanning electron microscopy (SEM) images were obtained for the cross section of the films after cryofracture of the samples to evaluate the microstructure, homogeneity, compactness, and compatibility of the different components. Uncoated samples were deposited directly on the carbon tape. SEM was performed using a tungsten cathode scanning electron microscope (Jeol, SM 6010LV /6010LA, Tokyo, Japan), and the images were obtained in secondary electron mode, using an acceleration voltage of $1 \mathrm{kV}$ and a working distance of $9 \mathrm{~mm}$.

Water vapour barrier properties were also measured for some selected films. The water vapour transmission rate (WVTR) expressed in $\mathrm{g} /\left(\mathrm{m}^{2}\right.$.day) and water vapour permeability (WVP) expressed in $\mathrm{g} /(\mathrm{Pa} \cdot \mathrm{day} \cdot \mathrm{m})$ were evaluated at $23 \pm 1{ }^{\circ} \mathrm{C}$ and $50 \pm 2 \% \mathrm{RH}$ by gravimetric method according to the standard protocol ASTM E96-00. The mass changes $(\Delta \mathrm{m})$ were monitored every hour for $48 \mathrm{~h}$. The WVTR was calculated by the ratio between the slope of the straight line $(\Delta \mathrm{m} / \Delta \mathrm{t})$ and the exposed film area in $\mathrm{m}^{2}$. WVP was calculated from the WVTR value by considering the thickness of the film [19].

\subsection{Statistical Analysis}

The experiments were performed in duplicate, and data were subjected to one-way analysis of variance (ANOVA) to analyse statistical differences between preparation methods and sample composition. Statistical significance was set at $p<0.05$ using SPSS (SPSS Inc., Chicago, IL, USA).

\section{Results and Discussion}

\subsection{CNF Preparation and Characterization}

Micro-/nanofibrillated celluloses were prepared following the procedures described above. The main properties of the obtained samples are summarized in Table 1.

Table 1. Characterization data of the obtained CNF samples.

\begin{tabular}{cccccccc}
\hline Sample & $\begin{array}{c}\text { Yield of } \\
\text { Fibrillation (\%) }\end{array}$ & $\begin{array}{c}\text { Degree of } \\
\text { Polymerization }\end{array}$ & $\begin{array}{c}\mathbf{C}_{\mathbf{C O O H}} \\
\mathbf{( m m o l} / \mathbf{g})\end{array}$ & $\begin{array}{c}\text { Transmittance, } \\
\mathbf{6 0 0} \mathbf{~ n m} \mathbf{( \% )}\end{array}$ & $\begin{array}{c}\text { Particle Size, } \\
\mathbf{D}_{\mathbf{0} \cdot \mathbf{5}}\end{array}$ & $\begin{array}{c}\text { Zeta Potential } \\
\mathbf{( m V )}\end{array}$ \\
\hline Mec & 6.5 & 2287 & 0.12 & 4 & $861 \pm 151$ & $-14 \pm 4$ \\
Enz & 16.6 & 960 & 0.14 & 8 & $436 \pm 49$ & $-18 \pm 2$ \\
TEMPO & 49.3 & 381 & 0.74 & 29 & $381 \pm 19$ & $-42 \pm 10$ \\
\hline
\end{tabular}

The yield of fibrillation obtained for the different CNF samples ranged from a very low fibrillation degree for the sample subjected only to the high-pressure homogenization step (Mec sample) to a moderate fibrillation degree for the sample pretreated with TEMPO radical and a relatively low quantity of sodium hypochlorite. These results were certainly correlated with the higher charge density induced by the high degree of substitution by carboxyl groups obtained for the sample oxidized by $\mathrm{NaClO}$ in the presence of TEMPO radical; in the latter case, the carboxyl groups were more abundant $(0.74 \mathrm{mmol} / \mathrm{g})$, and at a $\mathrm{pH}$ value above the $\mathrm{pKa}$ of the carboxylic acid ( $\mathrm{pKa}$ of $\mathrm{COOH} \mathrm{COO}^{-}$is ca. 4.8), the presence of a high content of ionized groups on the surface of the cellulose fibres led to the swelling of the fibres and facilitated the fibrillation during the high-pressure homogenization step [20]. However, the oxidation mediated by TEMPO also led to an 
accentuated decrease in the DP of cellulose, which occurred due to the degradation of the cellulose chains. The reduction of DP induced by TEMPO-mediated oxidation is frequently observed to be caused by the cleavage of the (1-4)- $\beta$-glycosidic bonds by active radical species that appear during the oxidation and/or by $\beta$-elimination due to the formation of aldehyde groups on the $\mathrm{C}_{6}$ as intermediate structures in alkaline $\mathrm{pH}$ conditions [21]. Additionally, the homogenization step can lead to some depolymerization of the oxidized fibres. On the other hand, the enzymatic pretreatment, which can hydrolyze selected external parts of the cellulose fibres and improve the accessibility to the fibrils, resulted in a slight increase in the yield of fibrillation and a decrease in the DP compared with the sample with only mechanical treatment.

The particle size obtained for TEMPO CNF was considerably smaller than that obtained for the sample prepared only by mechanical treatment. For CNF Enz, the particle size obtained was in between the CNF Mec and TEMPO CNF values, in line with the results obtained for the DP. In terms of surface charge, the value obtained for the TEMPO $\mathrm{CNF}$ was higher than those of the other two samples due to the larger presence of $\mathrm{COO}^{-}$ groups in the nanofibrils. As expected, derived from the smaller particle size and higher zeta potential, the transmittance of the TEMPO CNF suspension was higher than that of the other samples. This was the result of the presence of nanofibers of smaller dimensions and of the lower aggregation of nanofibers due to higher charge repulsion and counterion entropy, which led to better-dispersed particles that scatter less light and rendered the suspension less opaque.

\subsection{CNF-Based Composite Film Characterization}

\subsubsection{Optical Properties}

Suspension properties also have an impact on the materials produced, with the films obtained from TEMPO CNF more transparent than those obtained from CNF Mec or CNF Enz (Table 2 and Figure 2). On the other hand, the addition of sepiolite reduced the transparency of the films, this reduction being more pronounced when $50 \%$ of sepiolite was added to the films (Table 2). Sepiolite is an opaque and coloured material, and the incorporation of this mineral in the composite matrix led, therefore, to a higher light absorption/dispersion, this phenomenon being of potential interest to some applications where the UV radiation protection is important, such as food packaging [22]. It was also observed that, for each formulation type, the films prepared by filtration showed lower transparency than the films obtained by solvent casting, which is believed to be mainly a consequence of their larger basis weight (ca. 40 vs. $25 \mathrm{~g} / \mathrm{m}^{2}$, Table 2) and density.

Table 2. Basis weight, thickness, and optical properties of the obtained films.

\begin{tabular}{|c|c|c|c|c|c|c|}
\hline \multirow{2}{*}{ Film } & \multicolumn{2}{|c|}{ Basis Weight $\left(\mathrm{g} / \mathrm{m}^{2}\right)$} & \multicolumn{2}{|c|}{ Thickness $(\mu \mathrm{m})$} & \multicolumn{2}{|c|}{ Transparency (\%) } \\
\hline & SC & $\mathbf{F}+\mathbf{H P}$ & SC & $\mathbf{F}+\mathbf{H P}$ & SC & $\mathrm{F}+\mathrm{HP}$ \\
\hline $\mathrm{Mec}$ & $25.7 \pm 1.3$ & $40.5 \pm 0.5$ & $39.0 \pm 4.3(\mathrm{a})$ & $33.8 \pm 4.1(\mathrm{~d})$ & $68.5 \pm 5.8\left(\mathrm{a}^{\prime}\right)$ & $59.3 \pm 0.8\left(f^{\prime}\right)$ \\
\hline $\mathrm{Mec}+10 \% \mathrm{SEP}$ & $23.9 \pm 0.8$ & $40.2 \pm 1.4$ & $39.2 \pm 3.2(\mathrm{a})$ & $47.6 \pm 10.0$ (a) (b) (c) (d) & $62.5 \pm 0.7\left(\mathrm{~b}^{\prime}\right)$ & $43.4 \pm 8.8\left(\mathrm{c}^{\prime}\right)\left(\mathrm{d}^{\prime}\right)\left(\mathrm{g}^{\prime}\right)$ \\
\hline $\mathrm{Mec}+50 \% \mathrm{SEP}$ & $25.1 \pm 1.3$ & $37.6 \pm 1.1$ & $46.7 \pm 1.6(\mathrm{~b})$ & $44.5 \pm 4.9(\mathrm{~b})$ & $41.6 \pm 1.0\left(\mathrm{c}^{\prime}\right)$ & $27.6 \pm 1.2$ \\
\hline Enz & $24.7 \pm 1.5$ & $41.1 \pm 0.6$ & $37.9 \pm 3.9(\mathrm{a})$ & $33.2 \pm 1.8(\mathrm{~d})$ & $67.2 \pm 1.4\left(\mathrm{a}^{\prime}\right)$ & $60.5 \pm 0.3\left(b^{\prime}\right)$ \\
\hline Enz $+10 \%$ SEP & $25.8 \pm 1.5$ & $43.3 \pm 4.5$ & $42.1 \pm 1.3(\mathrm{c})$ & $41.5 \pm 2.9(\mathrm{c})$ & $61.6 \pm 1.9\left(\mathrm{~b}^{\prime}\right)$ & $49.5 \pm 2.8\left(\mathrm{~g}^{\prime}\right)$ \\
\hline Enz $+50 \%$ SEP & $25.1 \pm 1.7$ & $39.4 \pm 0.6$ & $47.7 \pm 4.8(\mathrm{~b})$ & $44.8 \pm 2.7(\mathrm{~b})$ & $43.7 \pm 1.5\left(\mathrm{~d}^{\prime}\right)$ & $31.2 \pm 0.2\left(\mathrm{~h}^{\prime}\right)$ \\
\hline TEMPO & $23.8 \pm 1.7$ & $40.8 \pm 0.8$ & $33.0 \pm 9.3(\mathrm{a})(\mathrm{c})(\mathrm{d})(\mathrm{e})$ & $39.1 \pm 4.8(\mathrm{a})$ & $84.1 \pm 0.9$ & $82.9 \pm 0.1$ \\
\hline TEMPO + $10 \%$ SEP & $23.9 \pm 1.9$ & $40.0 \pm 0.7$ & $25.4 \pm 3.8(\mathrm{e})$ & $36.4 \pm 0.8$ (a) & $78.5 \pm 2.2$ & $63.1 \pm 8.8\left(\mathrm{a}^{\prime}\right)\left(\mathrm{b}^{\prime}\right)\left(\mathrm{e}^{\prime}\right)\left(\mathrm{f}^{\prime}\right)$ \\
\hline TEMPO + 50\% SEP & $23.1 \pm 1.8$ & $39.7 \pm 2.3$ & $28.0 \pm 3.9(\mathrm{e})$ & $42.1 \pm 2.1(\mathrm{c})$ & $55.7 \pm 2.8\left(\mathrm{e}^{\prime}\right)$ & $31.8 \pm 4.1\left(\mathrm{~h}^{\prime}\right)$ \\
\hline
\end{tabular}

The properties of the films are also very dependent on the preparation procedure, as can be observed in Figure 2, with the films prepared by solvent casting more wrinkled compared with those obtained by filtration. This difficulty in obtaining films without wrinkles is even greater when sepiolite is added to the film formulations, mainly at high levels of incorporation (50\%). The films obtained by filtration are flatter and more regular compared with those obtained by solvent casting. Wrinkles in the film may have a negative impact not only on the optical properties but also on the mechanical performance of the 
films. Besides the better visual aspect, the preparation time was also significantly lower for the films prepared by filtration (30 times faster); additionally, this method allows the preparation of higher basis weight films.
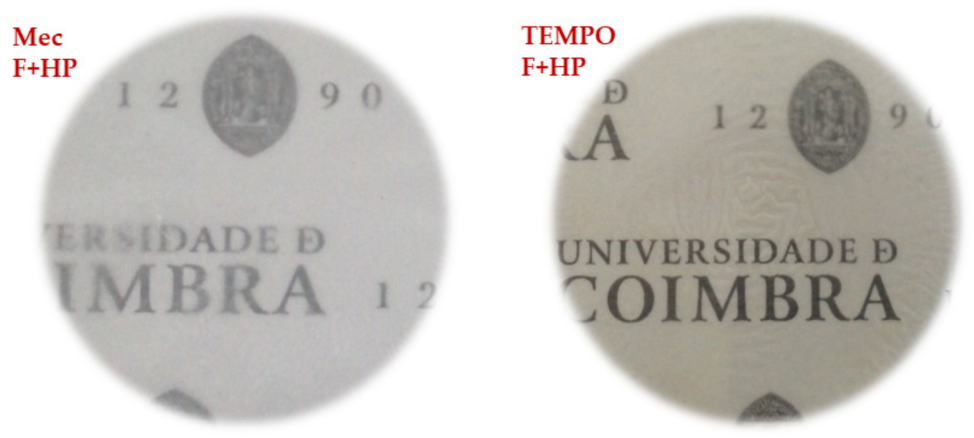

Figure 2. Digital photographs of the films prepared by filtration + hot pressing from CNF Mec (left) and TEMPO CNF (right).

\subsubsection{Mechanical Properties}

The mechanical properties obtained for the films prepared by solvent casting and filtration + hot pressing, without and with the addition of 10 and $50 \mathrm{wt} \%$ of sepiolite, are depicted in Figure 3.

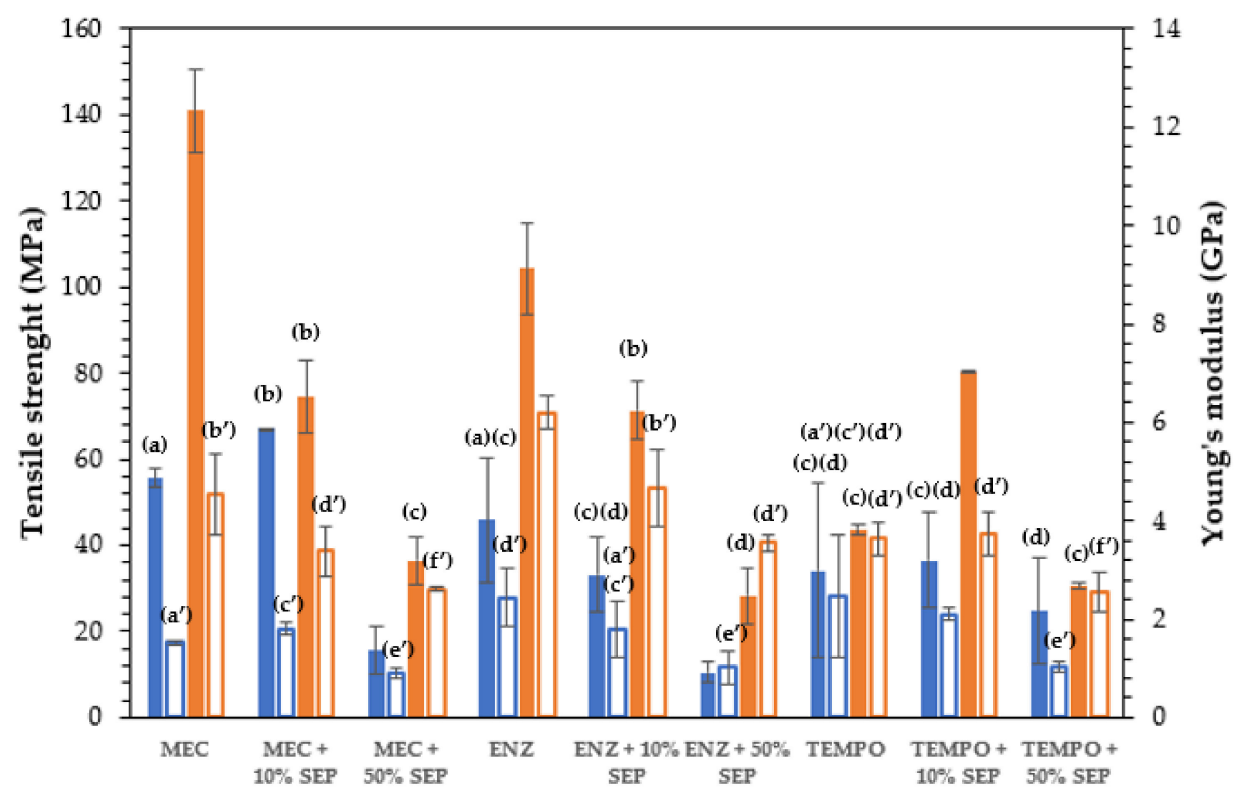

Figure 3. Mechanical properties of the films prepared by solvent casting (blue bars) and by filtration + hot pressing (orange bars). Tensile strength (full bars) and Young's modulus (empty bars). Same letter above the bars means no statistical difference $(p<0.05)$ between preparation methods (tensile strength: (a) to (d); Young's modulus: $\left(a^{\prime}\right)$ to $\left(f^{\prime}\right)$.

In general, it was observed that the films prepared by filtration followed by hot pressing presented better mechanical properties compared with the corresponding films prepared by solvent casting (i.e., both the tensile strength and Young's modulus were improved). Additionally, it was possible to infer that the incorporation of high contents of sepiolite (50\%) led to films of lower mechanical performance, but the presence of $10 \%$ sepiolite, in some cases, resulted in an increase in tensile strength compared with the respective net CNF films, namely, for CNF Mec $+10 \%$ sepiolite (solvent casting) and TEMPO $\mathrm{CNF}+10 \%$ sepiolite (filtration + hot pressing). This phenomenon is more pronounced in the case of TEMPO CNF, probably due to the higher degree of fibrillation, which results 
in fibrils of smaller dimensions and the possibility of a better entanglement of CNF and sepiolite fibres. Additionally, the mixture of charged CNF (TEMPO CNF) with clay minerals can result in a better dispersion state of the mineral and allow a good entanglement of the mineral and CNF [2]. A similar trend was observed in works dealing with films of TEMPO-oxidized CNF and montmorillonite, a planar clay mineral: an increase in tensile strength with the increment of clay content in the nanocomposite up to $10 \%$ [23]. The values reported for the tensile strength and Young's modulus were higher than those obtained in the present work, but it is important to note that this kind of layered clay minerals can be easily exfoliated and form exfoliated nanocomposites with good mechanical properties. Notwithstanding, compared with the results reported in the literature for ultrasoundassisted nanocomposite membranes of sepiolite and $\mathrm{CNF}$, our composites presented higher mechanical properties for all the combinations studied [24]. On the other hand, the addition of sepiolite to the films prepared by filtration also resulted in a decrease in the elongation at break (Appendix A, Table A1), with the decrease for $50 \%$ of sepiolite more pronounced for the cases of CNF Mec and Enz than for the case of TEMPO CNF. For the films prepared by solvent casting, this variation was not so obvious, and in fact, no decrease in the elongation at break was observed for $10 \%$ of sepiolite; for $50 \%$ of sepiolite, the elongation at break was reduced for CNF Mec and Enz but not for TEMPO CNF, where an apparent increase was found. The decrease in the elongation is indicative of a decrease in the ductility of the material and is probably related to changes in the interactions between the two involved fibrous components induced by formulation variations. It is important to note that CNF Mec presented particles of larger size; this is indicative of the presence of not only fibres/fibrils of longer size but also thicker fibres/fibrils when compared with TEMPO CNF. These longer and thicker fibres/fibrils can result in net CNF films with better mechanical properties, as observed for the tensile strength, but poor interaction with sepiolite is expected due to lower fibril content. Additionally, sepiolite fibres/bundles are more rigid than CNF fibres/fibrils. Thus, an increase in sepiolite content, mainly for the cases of formulations containing CNF with a low degree of fibrillation, is expected to lead to a decrease in the ductility of the material.

\subsubsection{Morphological Properties}

The surface and the cross section of the films prepared were observed by electron microscopy (Figures 4 and 5).

The surface and the cross section of the films obtained by solvent casting and filtration presented some differences. The images of the surface of the films prepared by solvent casting revealed an irregular wrinkled surface (Figure 4c), contrary to the surface of the films prepared by filtration (Figure 4d), which appeared very regular and smooth. Additionally, the cross section of the films showed differences, with the film prepared by filtration in an oriented layered structure (Figure $4 \mathrm{~b}$ ) and the film obtained by solvent casting in a less oriented organization (Figure 4a). In fact, the filtration process (Figure 1) can play a key role to form well-defined layers of CNF/CNF + sepiolite, and this will positively impact the mechanical properties of the films. On the other hand, the final hot-pressing step used for the films produced by filtration can perhaps explain the smoother and regular surface of these films.

Likewise, the microstructure and the surface of the prepared composite films were observed by SEM (Figure 5).

From the images obtained for the cross section of the composite films, no segregation between CNF and sepiolite was observed. Again, the films prepared by filtration appeared in a more structured organization in layers (Figure $5 b$ ), which led to better mechanical performance. It is important to note that the film prepared by filtration using TEMPO CNF and $10 \%$ sepiolite presented better mechanical properties (higher tensile strength) than that using net TEMPO CNF, whereas the corresponding films prepared by solvent casting showed similar mechanical properties (tensile strength and Young's modulus) to each other. This improvement was pronounced for the film prepared by filtration, perhaps due to the 
better alignment of the particles in the film. It is important to note that the incorporation of sepiolite in the films prepared using CNF Mec and Enz resulted in an increment trend in the thickness of the film for the same basis weight. This increment in thickness was not evident for the films prepared using TEMPO CNF, which can explain the lower decline in mechanical properties presented by the TEMPO CNF-based composite films. This difference in thickness increase by the addition of sepiolite can be probably explained by a better packing of the mineral and CNF particles due to the reduced dimensions and improved flexibility of TEMPO CNF fibrils, which also resulted in a highly entangled network and films with better mechanical properties with added sepiolite.
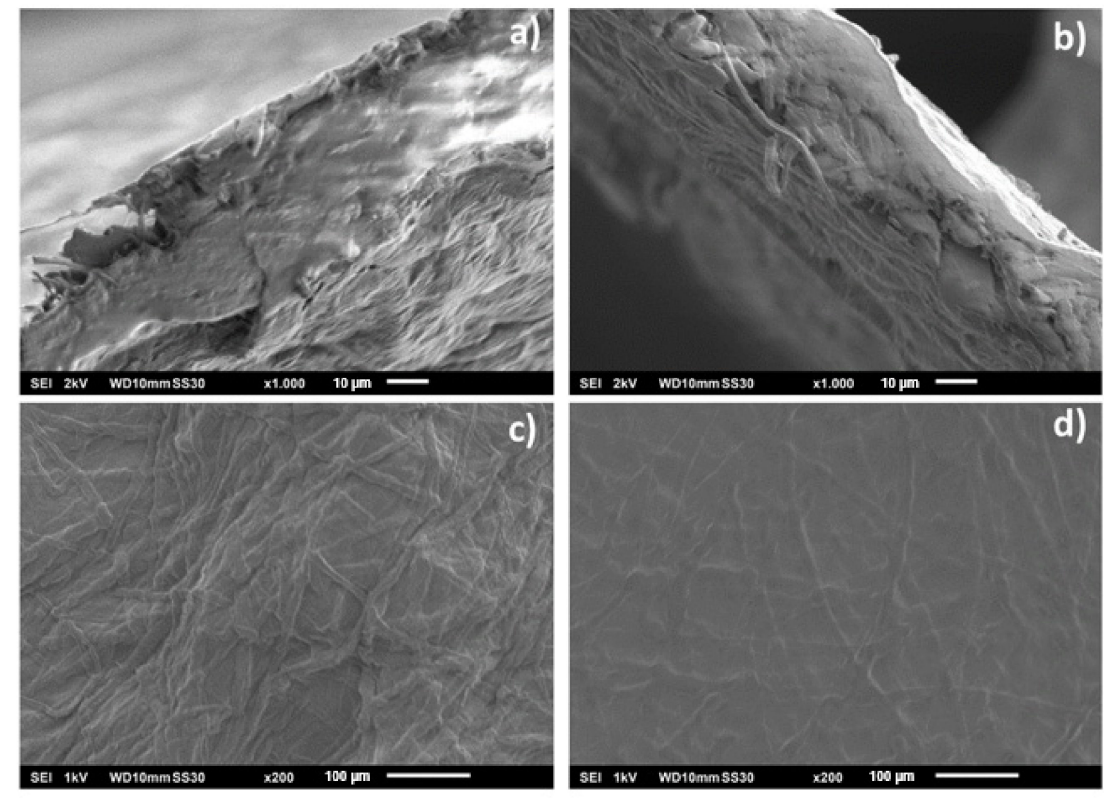

Figure 4. Scanning electron microscopy images of enzymatic CNF films prepared by solvent casting $(\mathbf{a}, \mathbf{c})$ and filtration + hot pressing $(\mathbf{b}, \mathbf{d})$. Cross section of the films $(\mathbf{a}, \mathbf{b})$; surface $(\mathbf{c}, \mathbf{d})$.
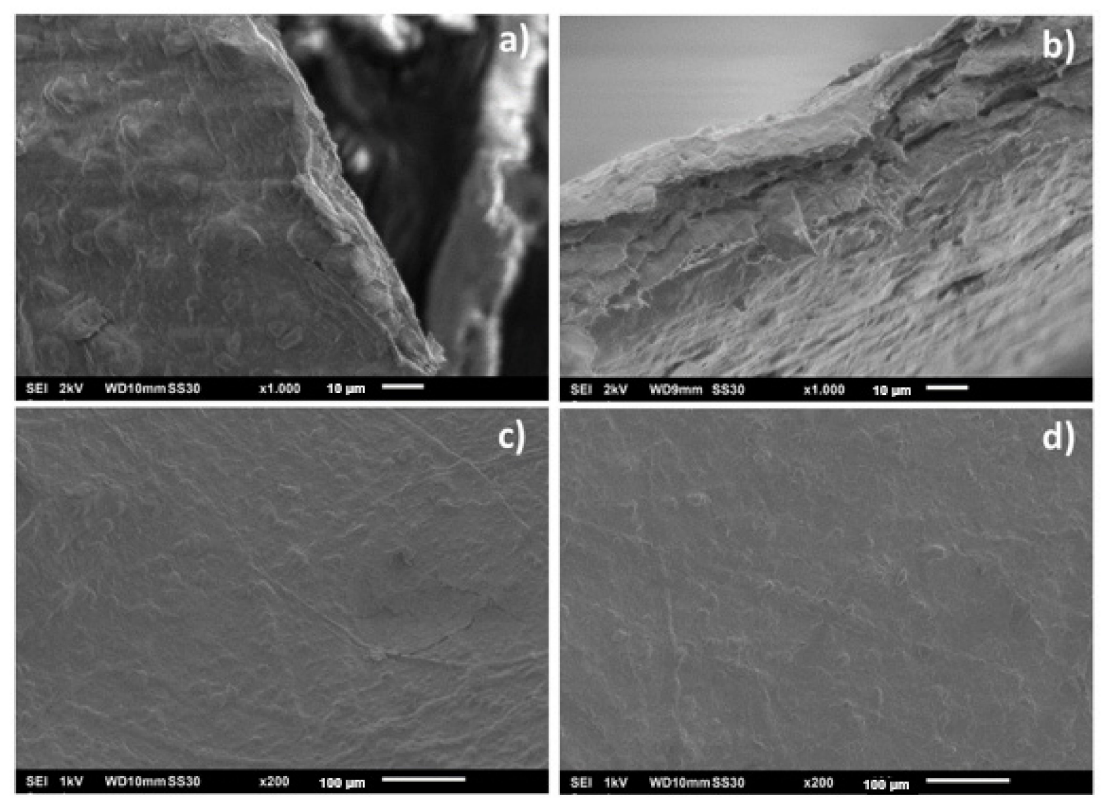

Figure 5. Scanning electron microscopy images of TEMPO CNF films containing 50\% sepiolite. Films prepared by solvent casting $(\mathbf{a}, \mathbf{c})$ and filtration + hot pressing $(\mathbf{b}, \mathbf{d})$. Cross section of the films $(\mathbf{a}, \mathbf{b})$; surface $(\mathbf{c}, \mathbf{d})$. 


\subsubsection{Barrier Properties}

The compactness of the films can also impact the barrier properties, with this property of major importance in food packaging. Table 3 summarizes the results obtained for the water vapour barrier properties of a few prepared films. In fact, an increment in water vapour transmission rate (WVTR) with the incorporation of sepiolite $(20 \%)$ was noticed up to $80 \%$ for the films prepared using CNF Enz. The same trend was observed for the films prepared using CNF Mec but with lower extension (about 30\%). For the films with TEMPO CNF, the incorporation of sepiolite seemed to have a slightly positive impact on the water vapour barrier. Overall, the obtained results are in line with or are even slightly better than the values reported in the literature for net CNF films or CNF/sepiolite composite films [24,25], with our films presenting a WVTR ranging from 184, 104, and $216 \mathrm{~g} \cdot \mathrm{m}^{-2} \cdot \mathrm{d}^{-1}$ (films of net CNF Mec, Enz, and TEMPO, respectively) to 233, 186, and $176 \mathrm{~g} \cdot \mathrm{m}^{-2} \cdot \mathrm{d}^{-1}$ (composite films prepared with CNF Mec, Enz, and TEMPO, respectively). The water vapour permeability (WVP) results showed a similar trend compared with the WVTR results, with an increase in WVP observed with the incorporation of sepiolite, with the exception of the films prepared with TEMPO CNF, in which a slight decrease was observed. Our composite films present WVP values in line with or even lower than those of plastics, such as polylactic acid (PLA), but higher than those of others, such as low-density polyethylene (LDPE) or polycaprolactone (PCL) [26,27], which means that our films present barrier properties similar to or better than those of PLA films, but worse than those of LDPE or PCL films.

Table 3. Barrier properties of the films obtained by filtration + hot pressing.

\begin{tabular}{|c|c|c|}
\hline Film & WVTR $\left(g \cdot m^{-2} \cdot d^{-1}\right)$ & $\mathrm{WVP} \times 10^{6}\left(\mathrm{~g} \cdot \mathrm{m} \cdot \mathrm{m}^{-2} \cdot \mathrm{d}^{-1} \cdot \mathrm{Pa}^{-1}\right)$ \\
\hline $\mathrm{Mec}$ & 184 & 7.3 \\
\hline $\mathrm{Mec}+20 \% \mathrm{SEP}$ & 233 & 8.3 \\
\hline Enz & 104 & 3.4 \\
\hline Enz $+20 \%$ SEP & 186 & 5.4 \\
\hline TEMPO & 216 & 6.5 \\
\hline TEMPO + 20\% SEP & 176 & 5.4 \\
\hline
\end{tabular}

\section{Conclusions}

The formulation and the preparation method play key roles in the properties of CNF-based composite films. The addition of sepiolite, a fibrous mineral, in general, led to a decrease in the mechanical performance (tensile strength and Young's modulus) of the films, except for the TEMPO CNF case, in which an improvement in tensile strength could be observed for a low level $(10 \%)$ of mineral incorporation. The higher degree of fibrillation of this CNF could justify this result by promoting the formation of an entangled network with the mineral fibres. A decrease in the film ductility was also observed, as measured by the decrease in the elongation at break of the films with the increase in the mineral content. Conversely, the water vapour barrier properties suffered a decrease by the incorporation of fibrous mineral into the composite formulations containing CNF Mec or CNF Enz. These could be due to changes in the film compactness, with the incorporation of the fibrous mineral, which allows the water molecules to better diffuse through the film and reduce the barrier properties. In contrast, for the films with TEMPO CNF, similar to the improvement in the strength properties, the water vapour barrier apparently underwent a slight improvement with the incorporation of sepiolite. Overall, the films prepared by filtration followed by hot pressing presented better mechanical properties and fewer wrinkles. This method allows the preparation of films in the fastest way compared with solvent casting, the most used technique, and the films are of better quality, being an interesting option for the preparation of this kind of materials. Nevertheless, it should be mentioned that this method may not be cheap compared with solvent casting, especially at the industrial level, due to the equipment necessary for its implementation. Finally, it can be said that the films prepared by filtration + hot pressing of net CNF Enz and TEMPO 
CNF containing a low amount of sepiolite $(10 \%-20 \%)$ overall have a better balance between mechanical, optical, and barrier properties.

Author Contributions: Conceptualization: L.A. and J.A.F.G.; investigation: L.A., A.R., C.V. and J.A.F.G.; methodology: L.A.; writing—original draft: L.A.; review and editing: L.A., A.R., C.V., E.F., M.G.R., P.J.T.F., M.L.P. and J.A.F.G.; funding acquisition: M.G.R., E.F. and J.A.F.G.; project administration, J.A.F.G. All authors have read and agreed to the published version of the manuscript.

Funding: The present research was supported by the R\&D Project "FILCNF-New generation of composite films of cellulose nanofibrils with mineral particles as high strength materials with gas barrier properties" (PTDC/QUI-OUT/31884/2017, CENTRO 01-0145-FEDER-031884), CIEPQPF Strategic Research Project (UIDB/00102/2020), and Techn\&Art Research Project (UIDB/05488/2020) funded by the Fundação para a Ciência e Tecnologia (FCT) and FEDER.

Institutional Review Board Statement: Not applicable.

Informed Consent Statement: Not applicable.

Data Availability Statement: Not applicable.

Acknowledgments: The authors acknowledge Julio Santarén for the collaboration and discussions on the dispersion of sepiolite in aqueous medium.

Conflicts of Interest: The authors declare no conflict of interest.

\section{Appendix A}

Table A1. Maximum force and elongation at break of the different films.

\begin{tabular}{ccccc}
\hline \multirow{2}{*}{ Sample } & \multicolumn{2}{c}{ Solvent Casting } & \multicolumn{2}{c}{ Filtration + Hot Pressing } \\
\cline { 2 - 5 } & Force Max. (N) & Elongation at Break (\%) & Force Max. (N) & Elongation at Break (\%) \\
\hline Mec & 32.7 & 5.6 & 71.5 & 10.5 \\
Mec + 10\% Sep & 38.7 & 6.7 & 53.2 & 7.2 \\
Mec + 50\% Sep & 14.2 & 3.5 & 24.4 & 2.8 \\
Enz & 24.5 & 2.5 & 51.9 & 5.0 \\
Enz + 10\% Sep & 24.7 & 2.8 & 44.4 & 3.8 \\
Enz + 50\% Sep & 8.7 & 1.7 & 25.6 & 1.3 \\
TEMPO & 15.1 & 1.5 & 43.9 & 2.3 \\
TEMPO + 10\% Sep & 13.5 & 1.7 & 19.3 & 1.2 \\
TEMPO + 50\% Sep & 14.2 & 3.5 & & 1.5 \\
\hline
\end{tabular}

\section{References}

1. Ayuso, C.F; Agüero, A.A.; Hernández, J.A.P.; Santoyo, A.B.; Gómez, E.G. High oxygen barrier polyethylene films. Polym. Polym. Compos. 2017, 25, 571-582. [CrossRef]

2. Alves, L.; Ferraz, E.; Gamelas, J.A.F. Composites of nanofibrillated cellulose with clay minerals: A review. Adv. Colloid Interface Sci. 2019, 272, 101994. [CrossRef] [PubMed]

3. Gamelas, J.A.F; Ferraz, E. Composite films based on nanocellulose and nanoclay minerals as high strength materials with gas barrier capabilities: Key points and challenges. BioResources 2015, 10, 6310-6313. [CrossRef]

4. Magalhães, S.; Alves, L.; Medronho, B.; Romano, A.; Rasteiro, M.d.G. Microplastics in ecosystems: From current trends to bio-based removal strategies. Molecules 2020, 25, 3954. [CrossRef]

5. Mahalik, N.P.; Nambiar, A.N. Trends in food packaging and manufacturing systems and technology. Trends Food Sci. Technol. 2010, 21, 117-128. [CrossRef]

6. Zeng, J.; Zeng, Z.; Cheng, Z.; Wang, Y.; Wang, X.; Wang, B.; Gao, W. Cellulose nanofibrils manufactured by various methods with application as paper strength additives. Sci. Rep. 2021, 11, 11918. [CrossRef]

7. González del Campo, M.M.; Darder, M.; Aranda, P.; Akkari, M.; Huttel, Y.; Mayoral, A.; Bettini, J.; Ruiz-Hitzky, E. Functional hybrid nanopaper by assembling nanofibers of cellulose and sepiolite. Adv. Funct. Mater. 2018, 28, 1703048. [CrossRef]

8. Bardet, R.; Reverdy, C.; Belgacem, N.; Leirset, I.; Syverud, K.; Bardet, M.; Bras, J. Substitution of nanoclay in high gas barrier films of cellulose nanofibrils with cellulose nanocrystals and thermal treatment. Cellulose 2015, 22, 1227-1241. [CrossRef]

9. Liu, A.; Berglund, L.A. Fire-retardant and ductile clay nanopaper biocomposites based on montmorrilonite in matrix of cellulose nanofibers and carboxymethyl cellulose. Eur. Polym. J. 2013, 49, 940-949. [CrossRef] 
10. Qin, S.; Pour, M.G.; Lazar, S.; Köklükaya, O.; Gerringer, J.; Song, Y.; Wågberg, L.; Grunlan, J.C. Super gas barrier and fire resistance of nanoplatelet/nanofibril multilayer thin films. Adv. Mater. Interfaces 2019, 6, 1801424. [CrossRef]

11. Castro, D.O.; Karim, Z.; Medina, L.; Häggström, J.O.; Carosio, F.; Svedberg, A.; Wågberg, L.; Söderberg, D.; Berglund, L.A. The use of a pilot-scale continuous paper process for fire retardant cellulose-kaolinite nanocomposites. Compos. Sci. Technol. 2018, 162, 215-224. [CrossRef]

12. Ghanadpour, M.; Carosio, F.; Ruda, M.C.; Wågberg, L. Tuning the nanoscale properties of phosphorylated cellulose nanofibrilbased thin films to achieve highly fire-protecting coatings for flammable solid materials. ACS Appl. Mater. Interfaces 2018, 10, 32543-32555. [CrossRef]

13. Guggenheim, S.; Krekeler, M.P.S. Chapter 1-The structures and microtextures of the palygorskite-sepiolite group minerals. In Developments in Clay Science; Galàn, E., Singer, A., Eds.; Elsevier: Amsterdam, The Netherlands, 2011; Volume 3, pp. 3-32. [CrossRef]

14. Pinto, L.; Bonifacio, M.A.; De Giglio, E.; Santovito, E.; Cometa, S.; Bevilacqua, A.; Baruzzi, F. Biopolymer hybrid materials: Development, characterization, and food packaging applications. Food Packag. Shelf Life 2021, 28, 100676. [CrossRef]

15. Lourenço, A.F.; Gamelas, J.A.F.; Nunes, T.; Amaral, J.; Mutjé, P.; Ferreira, P.J. Influence of TEMPO-oxidised cellulose nanofibrils on the properties of filler-containing papers. Cellulose 2017, 24, 349-362. [CrossRef]

16. Lourenço, A.F.; Gamelas, J.A.F.; Sarmento, P.; Ferreira, P.J.T. Enzymatic nanocellulose in papermaking-The key role as filler flocculant and strengthening agent. Carbohydr. Polym. 2019, 224, 115200. [CrossRef]

17. Saito, T.; Kimura, S.; Nishiyama, Y.; Isogai, A. Cellulose nanofibers prepared by TEMPO-mediated oxidation of native cellulose. Biomacromolecules 2007, 8, 2485-2491. [CrossRef]

18. Henriksson, M.; Berglund, L.A.; Isaksson, P.; Lindström, T.; Nishino, T. Cellulose nanopaper structures of high toughness. Biomacromolecules 2008, 9, 1579-1585. [CrossRef]

19. Almeida, R.O.; Ramos, A.; Alves, L.; Potsi, E.; Ferreira, P.J.T.; Carvalho, M.G.V.S.; Rasteiro, M.G.; Gamelas, J.A.F. Production of nanocellulose gels and films from invasive tree species. Int. J. Biol. Macromol. 2021, 188, 1003-1011. [CrossRef]

20. Saito, T.; Nishiyama, Y.; Putaux, J.-L.; Vignon, M.; Isogai, A. homogeneous suspensions of individualized microfibrils from tempo-catalyzed oxidation of native cellulose. Biomacromolecules 2006, 7, 1687-1691. [CrossRef]

21. Serra, A.; González, I.; Oliver-Ortega, H.; Tarrès, Q.; Delgado-Aguilar, M.; Mutjé, P. Reducing the amount of catalyst in tempo-oxidized cellulose nanofibers: Effect on properties and cost. Polymers 2017, 9, 557. [CrossRef]

22. Ruiz-Hitzky, E.; Darder, M.; Alcântara, A.C.S.; Wicklein, B.; Aranda, P. Chapter 1-Functional nanocomposites based on fibrous clays. In Functional Polymer Composites with Nanoclays; Lvov, Y., Guo, B., Fakhrullin, R.F., Eds.; The Royal Society of Chemistry: Cambridge, UK, 2017; pp. 1-53. [CrossRef]

23. Xu, D.; Wang, S.; Berglund, L.A.; Zhou, Q. Surface charges control the structure and properties of layered nanocomposite of cellulose nanofibrils and clay platelets. ACS Appl. Mater. Interfaces 2021, 13, 4463-4472. [CrossRef] [PubMed]

24. González del Campo, M.M.; Caja-Munoz, B.; Darder, M.; Aranda, P.; Vázquez, L.; Ruiz-Hitzky, E. Ultrasound-assisted preparation of nanocomposites based on fibrous clay minerals and nanocellulose from microcrystalline cellulose. Appl. Clay Sci. 2020, 189 , 105538. [CrossRef]

25. Honorato, C.; Kumar, V.; Liu, J.; Koivula, H.; Xu, C.; Toivakka, M. Transparent nanocellulose-pigment composite films. J. Mater Sci. 2015, 50, 7343-7352. [CrossRef]

26. Yun, X.; Dong, T. 5-Fabrication of high-barrier plastics and its application in food packaging. In Food Packaging; Grumezescu, A.M., Ed.; Academic Press: Cambridge, MA, USA, 2017; pp. 147-184. [CrossRef]

27. Carosio, F.; Colonna, S.; Fina, A.; Rydzek, G.; Hemmerlé, J.; Jierry, L.; Schaaf, P.; Boulmedais, F. Efficient gas and water vapor barrier properties of thin poly(lactic acid) packaging films: Functionalization with moisture resistant nafion and clay multilayers. Chem. Mater. 2014, 26, 5459-5466. [CrossRef] 